\title{
Determination of hydroxyl radicals in advanced oxidation processes with dimethyl sulfoxide trapping and liquid chromatography
}

\author{
Chao Tai ${ }^{\mathrm{a}}$, Jin-Feng Peng ${ }^{\mathrm{a}}$, Jing-Fu Liu ${ }^{\mathrm{a}}$, Gui-Bin Jiang ${ }^{\mathrm{a}, *}$, Hong Zou ${ }^{\mathrm{b}}$ \\ ${ }^{a}$ Key Laboratory of Environmental Chemistry and Ecotoxicology, Research Center for Eco-Environmental Sciences, Chinese Academy of Sciences, \\ PO Box 2871, Beijing 100085, PR China \\ ${ }^{\mathrm{b}}$ Department of Chemistry of Capital Normal University, Beijing 100037, PR China
}

Received 5 May 2004; received in revised form 5 August 2004; accepted 5 August 2004

Available online 1 October 2004

\begin{abstract}
In this paper, a simple and sensitive method for the determination of hydroxyl radicals generated in advanced oxidation processes is described. The proposed method employed the reaction between hydroxyl radicals and dimethyl sulfoxide (DMSO) to generate quantitatively formaldehyde, which then reacted with 2,4-dinitrophenylhydrazine (DNPH) to form the corresponding hydrazone (HCHO-DNPH) and analyzed by liquid chromatography-UV. Factors affecting the derivatization reaction of HCHO and trapping reaction of hydroxyl radicals, as well as the applicability of the method, were investigated. The detection limit for hydroxyl radicals was $0.54 \mu \mathrm{mol} \mathrm{L}-1$. The method had been used to determine the yield of hydroxyl radicals in various advanced oxidation processes (AOPs) to compare their oxidation ability.
\end{abstract}

(C) 2004 Elsevier B.V. All rights reserved.

Keywords: Hydroxyl radicals; AOPs; Dimethyl sulfoxide; Formaldehyde; 2,4-Dinitrophenylhydrazine; LC

\section{Introduction}

During the last two decades, advanced oxidation processes (AOPs) have attracted an increasing scientific and technique attention for water decontamination. In these processes, the hydroxyl radicals, generated from ozonation [1], $\mathrm{UV} / \mathrm{H}_{2} \mathrm{O}_{2}$ [2], $\mathrm{UV} / \mathrm{Fe}^{3+} / \mathrm{H}_{2} \mathrm{O}_{2}$ [3], $\mathrm{UV} / \mathrm{TiO}_{2}$ [4], Fenton reaction [5], Fenton-like reaction [6] and other systems [7], play an important role in degradation of organic substances in water. It is of continuous interest to find new efficient chemical or physical systems to generate hydroxyl radicals for water treatment. In most papers reported, the degradation efficiency is evaluated through the post-process determination of residuals or intermediates, which is time-consuming and inefficient. More important, the degradation efficiency of organic compound depends greatly on the character of the compound. Some systems show high efficiency for one kind of substances, but

\footnotetext{
* Corresponding author. Tel.: +86 1062923477.

E-mail address: gbjiang@mail.rcees.ac.cn (G.-B. Jiang).
}

low or no effect for another $[6,8]$. Therefore, quantitative determination of the generation rate and the concentrations of hydroxyl radicals in the advanced treatment processes is necessary for a better understanding of degradation efficiency of different systems and to what extent the hydroxyl radicals involving in the degradation of pollutants $[9,10]$.

Current methods for the detecting hydroxyl radicals suffer from one or more problems. One of the methods is the electron spin resonance spectroscopy (ESR), which measures the electron paramagnetic resonance spectrum of a spin adduct derivative after trapping $[11,12]$. But this method is insensitive and cannot be employed readily to acquire quantitative estimate of ${ }^{\bullet} \mathrm{OH}$ production because the ${ }^{\bullet} \mathrm{OH}$ adduct is not stable. Besides, the expensive instruments make it unsuitable for routine analysis. Another method is aromatic hydroxylation, in which the hydroxylated products generating from the reaction of hydroxyl radicals with aromatic compounds, such as phenol, benzoic acid or salicylic acid, are separated by gas chromatography (GC) or liquid chromatography (LC) and detected with different detector [13-16]. Though this method is 
handy and sensitive, there are some problems associated with its use in the detection of hydroxyl radicals in AOPs. These include the following: (i) multiple reaction products; (ii) secondary generation of superoxide; (iii) limited solubility; and (iv) forming complex with iron (II, III), such as salicylic acid, to influence the determination of hydroxyl radicals in Fenton and Fenton-like reaction [17].

Dimethyl sulfoxide (DMSO) has great advantages as a molecular probe for the detection of the hydroxyl radicals in AOPs. First, DMSO is highly water soluble to trap most hydroxyl radicals generated in AOPs. Secondly, it cannot form complexes with iron or other metal ions to influence the detection of ${ }^{\bullet} \mathrm{OH}$ in Fenton and Fenton-like reactions. Thirdly, it is nontoxic at relatively high concentrations, which makes it suitable to determine ${ }^{\bullet} \mathrm{OH}$ in some AOPs involving microorganism $[18,19]$. Fourthly, it is highly reactive with the hydroxyl radicals $\left(k=4.5 \sim 7.1 \times 10^{9} \mathrm{~mol} \mathrm{~L}^{-1} \mathrm{~s}^{-1}\right)$ forming methanesulfinic acid (MSA), methyl radicals and formaldehyde [20-23]:

$$
\begin{aligned}
& \bullet \mathrm{OH}+\left(\mathrm{CH}_{3}\right)_{2} \mathrm{SO} \rightarrow \mathrm{CH}_{3} \mathrm{SO}_{2} \mathrm{H}+{ }^{\bullet} \mathrm{CH}_{3} \\
& { }^{\bullet} \mathrm{CH}_{3}+\mathrm{H}-\mathrm{R} \rightarrow \mathrm{CH}_{4}+{ }^{\bullet} \mathrm{R} \\
& { }^{\bullet} \mathrm{CH}_{3}+\mathrm{O}_{2} \rightarrow \mathrm{CH}_{3} \mathrm{OO}{ }^{\bullet} \\
& 2 \mathrm{CH}_{3} \mathrm{OO} \cdot \rightarrow \mathrm{HCHO}+\mathrm{CH}_{3} \mathrm{OH}+\mathrm{O}_{2}
\end{aligned}
$$

In the past decades, methanesulfinic acid has been adopted for determination of hydroxyl radicals by spectphotometric method [20,21] and HPLC [22,23]. However, recent study $[24,25]$ indicates that methanesulfinic acid is only an intermediate product, which also reacted rapidly with hydroxyl radicals leading to methanesulfonic acid and sulfate formation $\left(k=6.2 \sim 12 \times 10^{9} \mathrm{~mol} \mathrm{~L}^{-1} \mathrm{~s}^{-1}\right)$. Another highly sensitive method based on methyl radicals reacting with a fluorescamine-derivatized nitroxide forming a stable $o$ methylhydroxylamine, has been developed for the determination of hydroxyl radicals in biological systems $[17,26]$. Since it was found that the methane generated by the hydrogen extraction of methyl radicals (Reaction 2) was only $0.3-0.5 \%$ of the formaldehyde producing by the reaction of methyl radicals and oxygen (Reactions 3 and 4), formaldehyde, generated in the $\mathrm{DMSO} /{ }^{\bullet} \mathrm{OH}$ system, was also used to detect hydroxyl radicals. Based on the Hantzsch reaction of formaldehyde, ammonia and acetylacetone, a fluorescence method was proposed for the determination of hydroxyl radicals by Klein et al. [27]. Though this method is simple and sensitive, it needed high temperature $\left(60-90^{\circ} \mathrm{C}\right)$ and long time for Hantzsch reaction (30-60 min).

This paper aims to develop a sensitive method available readily for the determination of hydroxyl radicals in AOPs. The proposed method is based on the reaction between hydroxyl radicals and DMSO to produce formaldehyde quantitatively, which then reacts with 2,4-dinitrophenylhydrazine (DNPH) to form the corresponding hydrazone (DNPHo) $[28,29]$ and analyzed by LC-UV. The quantitative analysis of hydroxyl radicals can be done through the determination of the concentration of formaldehyde. The method has been used to investigate the generation rate of hydroxyl radicals in different advanced treatment processes.

\section{Experimental}

\subsection{Apparatus}

The HPLC equipment used was an Agilent 1100 LC including a BinPump and a VWD detector. The VWD detector was set at $355 \mathrm{~nm}$. The system has an injection value with a $20 \mu \mathrm{L}$ loop. An Agilent Zorbax Eclipse XDB-C18 column $(150 \times 4.6 \mathrm{~mm}$, particle size $5 \mu \mathrm{m})$ was used as analytical column. To perform the isocratic elution at a flow rate of $1.0 \mathrm{~mL} / \mathrm{min}$, a mixture of methanol and water $(60: 40, \mathrm{v} / \mathrm{v})$ was used as mobile phase. Both solvents were previously filtered through a $0.45 \mu \mathrm{m}$ PTFE filter and degassed ultrasonically.

\subsection{Chemicals and reagents}

Deionized water used in all experiments was purified with a Milli-Q water ion-exchange system. All chemicals were of ACS reagent grade. Formaldehyde standards were obtained from the National Research Center for Reference Material (Beijing, China). Working solutions $\left(0.1\right.$ and $\left.4 \mathrm{mmol} \mathrm{L}^{-1}\right)$ were prepared daily by appropriate dilution of the stock solutions with water. Analytical grade DNPH was obtained from Beijing Chemicals Corporation (Beijing, China) and was dissolved in acetonitrile to prepare a $6 \mathrm{mmol} \mathrm{L}^{-1}$ solution. By dissolving $0.078 \mathrm{~g}\left(\mathrm{NH}_{4}\right)_{2} \mathrm{Fe}\left(\mathrm{SO}_{4}\right)_{2} \cdot 6 \mathrm{H}_{2} \mathrm{O}, 0.081 \mathrm{~g}$ $\mathrm{Fe}\left(\mathrm{NO}_{3}\right)_{3} \cdot 9 \mathrm{H}_{2} \mathrm{O}$, and the according ligands (iron: ligand = $1: 3, \mathrm{~mol} / \mathrm{mol}$ ) in $100 \mathrm{~mL}$ water, $2 \mathrm{mmol} \mathrm{L}^{-1}$ ferrous, ferric and their complexes solutions were prepared. The ligands used are: ethylene diamine tetraacetate (EDTA) and bipyridine (bipy).

\subsection{Generation and trapping of $\bullet \mathrm{OH}$}

Different systems as reported are used as the source of hydroxyl radicals. They are (1) $\mathrm{Fe}^{2+} / \mathrm{H}_{2} \mathrm{O}_{2}$ [5]; (2) $\mathrm{Fe}^{3+} / \mathrm{H}_{2} \mathrm{O}_{2}$ [6]; (3) $\mathrm{Fe}^{2+}-E D T A / \mathrm{H}_{2} \mathrm{O}_{2}$; (4) $\mathrm{Fe}^{3+}-\mathrm{EDTA} / \mathrm{H}_{2} \mathrm{O}_{2}$ [30]; (5) $\mathrm{Fe}^{2+}$-bipy $/ \mathrm{H}_{2} \mathrm{O}_{2}$; (6) $\mathrm{Fe}^{3+}$-bipy/ $\mathrm{H}_{2} \mathrm{O}_{2}$ [31]; (7) $\mathrm{UV}-\mathrm{H}_{2} \mathrm{O}_{2}$; and (8) $\mathrm{UV}-\mathrm{Fe}^{2+} / \mathrm{H}_{2} \mathrm{O}_{2}$ [3]. The reaction mixture contained $250 \mathrm{mmol} \mathrm{L}^{-1}$ DMSO, $0.2 \mathrm{mmol} \mathrm{L}^{-1} \mathrm{Fe}^{2+}, \mathrm{Fe}^{3+}$ or their complexes, and $8 \mathrm{mmol} \mathrm{L}^{-1} \mathrm{H}_{2} \mathrm{O}_{2}$. The generation of hydroxyl radicals by $\mathrm{UV}-\mathrm{H}_{2} \mathrm{O}_{2}$ and $\mathrm{UV}-\mathrm{Fe}^{2+} / \mathrm{H}_{2} \mathrm{O}_{2}$ were carried out under a $40 \mathrm{~W}$ ultraviolet lamp with an irradiation area of $0.79 \mathrm{~cm}^{2}$. The mixture (final volume $2 \mathrm{~mL}, \mathrm{pH} 7.0$ ) was maintained at $25^{\circ} \mathrm{C}$ for a certain time, then $2.5 \mathrm{~mL}$ pH $4.0 \mathrm{H}_{3} \mathrm{PO}_{4}-\mathrm{NaH}_{2} \mathrm{PO}_{4}$ and $0.2 \mathrm{~mL} 6 \mathrm{mmol} \mathrm{L}^{-1} \mathrm{DNPH}$ was added and diluted to $5 \mathrm{~mL}$. The mixture was maintained at room temperature for $30 \mathrm{~min}$ and analyzed by LC-UV. 


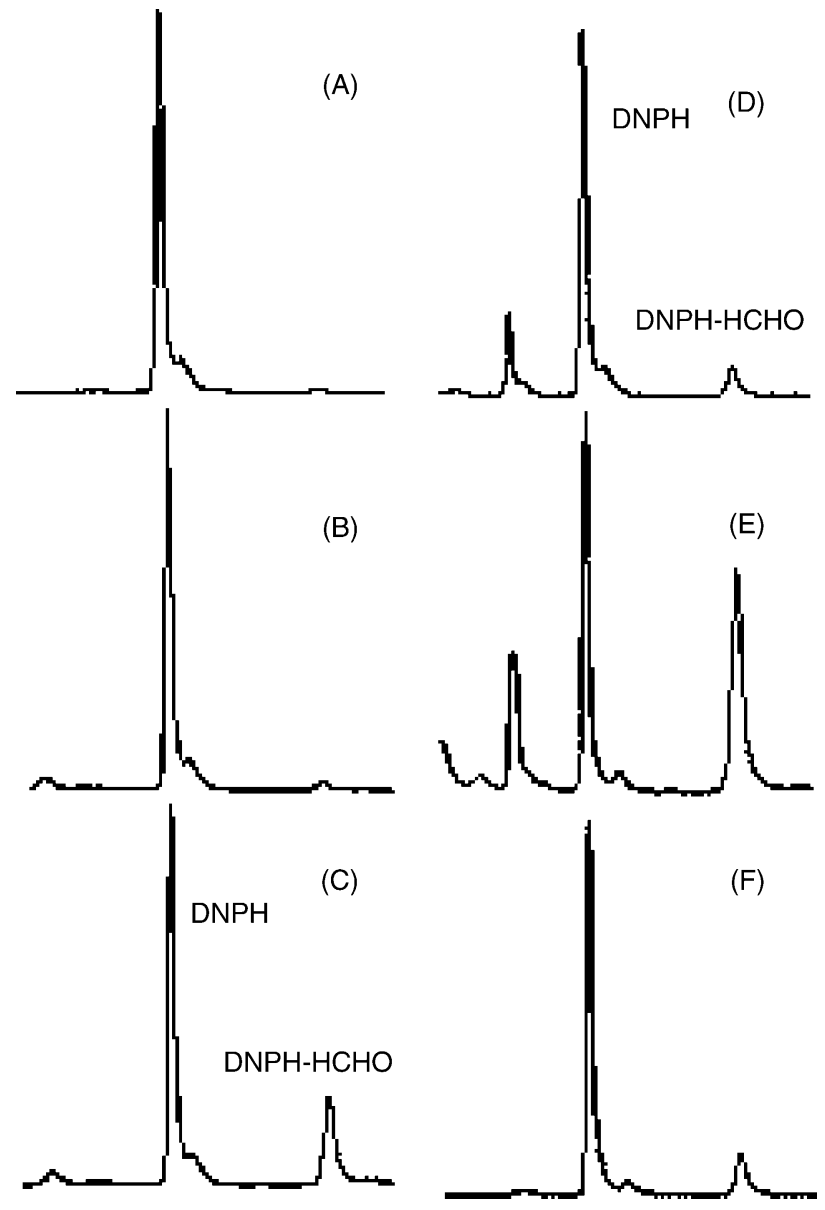

Fig. 1. Chromatograms of the HCHO-DNPH solutions obtained for blank (A), standard solution (B, $\left.4 \mu \mathrm{mol} \mathrm{L}{ }^{-1}\right)$, standard solution $\left(\mathrm{C}, 40 \mu \mathrm{mol} \mathrm{L}^{-1}\right.$ ), Fenton reaction (D), $\mathrm{Fe}^{3+}$-bipy/ $\mathrm{H}_{2} \mathrm{O}_{2}$ system (E) and $\mathrm{UV}-\mathrm{H}_{2} \mathrm{O}_{2}$ system (F).

\section{Results and discussion}

\subsection{HPLC analysis}

Under the selected experimental conditions, DNPH and HCHO-DNPH are well separated within 7 min using an Agilent Zorbax Eclipse XDB-C18 column. With the mobile phase of methanol-water (60: 40, v/v), and a flow-rate of $1 \mathrm{~mL} / \mathrm{min}$ the retention times were about 2.7 and $5.4 \mathrm{~min}$ for DNPH and HCHO-DNPH derivatives, respectively. Fig. 1 shows the typical liquid chromatograms of HCHO-DNPH solutions, obtained for blank, standard solution and produced from the oxidation of DMSO by different AOPs system in $60 \mathrm{~min}$.

\subsection{Derivatization procedure of $\mathrm{HCHO}$}

\subsubsection{Effect of DNPH concentration}

The optimization of derivatizing reagent concentration was conducted in $5 \mathrm{~mL}$ of $\mathrm{pH} 4.0 \mathrm{H}_{3} \mathrm{PO}_{4}-\mathrm{NaH}_{2} \mathrm{PO}_{4}$ buffer solution spiked with formaldehyde and DNPH, and with a derivatization time of $30 \mathrm{~min}$. Experiments revealed that when $80 \mu \mathrm{mol} \mathrm{L}^{-1}$ of formaldehyde was reacted, the peak area increased with DNPH concentration in the range of $0-160 \mu \mathrm{mol} \mathrm{L}^{-1}$, and kept constant when the concentration of DNPH was above $160 \mu \mathrm{mol} \mathrm{L}^{-1}$. Therefore, $240 \mu \mathrm{mol} \mathrm{L}^{-1}$ of DNPH was adopted in the following studies.

\subsubsection{Effect of $p H$}

Phosphonic acid (sulfuric acid) and sodium hydroxide were chosen to adjust the $\mathrm{pH}$ in the range of $1-7$. Fig. 2 shows the effect of the $\mathrm{pH}$ on the peak area of HCHO-DNPH. The peak area increased drastically with $\mathrm{pH}$ from 1 to 2 , kept almost constant from 2 to 6 , and dropped sharply above 6 . The optimal $\mathrm{pH}$ for the reaction of formaldehyde and DNPH was 2 to 6 . In the following studies, $\mathrm{pH} 4.0 \mathrm{H}_{3} \mathrm{PO}_{4}-\mathrm{NaH}_{2} \mathrm{PO}_{4}$ buffer solution was selected.

\subsubsection{Effect of derivatization temperature and time}

The temperature usually proposed in the literature is $40^{\circ} \mathrm{C}$ [28]. Experiments performed at this temperature gave similar results compared to those obtained at room temperature. Therefore, room temperature was selected to make the experimental procedure easier. The effect of reaction time on the yield of HCHO-DNPH derivative at room temperature was thus investigated. The peak area of HCHO-DNPH increased drastically with reaction time from 0 to $15 \mathrm{~min}$, and kept almost constant after 20 min reaction (Fig. 3), and 30 min was selected in the following studies.

\subsection{Linearity, detection limit and precision}

The calibration curve was plotted taking peak area of the HCHO-DNPH derivative. The solutions containing formaldehyde range from 5 to $800 \mathrm{nmol}$ in $5 \mathrm{~mL}$ were analyzed. The regression equation is $Y=19.4+2.02 X$, where $X$ is amount of formaldehyde (nmol) and $Y$ is the peak area, with a correlation coefficient of $\gamma=0.9993$. The detection limit calculated based on three times of the standard deviation divided by the slope of the calibration curve was $0.27 \mu \mathrm{mol} \mathrm{L}^{-1}$. The detection limit for hydroxyl radicals can be calculated according the Eqs. (1), (3) and (4), which indicate 1 mol of formaldehyde is generated from $2 \mathrm{~mol}$ of hydroxyl radicals reacting with DMSO, with a result of $0.54 \mu \mathrm{mol} \mathrm{L}^{-1}$. Five measurements of ${ }^{\bullet} \mathrm{OH}$ producing from $\mathrm{Fe}^{3+}$-bipy/ $\mathrm{H}_{2} \mathrm{O}_{2}$ system in 60 min gave an RSD of 3.8\%.

\subsection{Effect of DMSO concentration on trapping of $\bullet$ and the recovery of $\mathrm{HCHO}$}

It is necessary to use a concentration of DMSO high enough to trap most hydroxyl radicals and prevent the sidereaction of hydroxyl radicals with other species in the system. The formation rate of HCHO on DMSO concentration in different systems was investigated. The results are shown in Fig. 4. In the absence of DMSO, HCHO-DNPH was not 


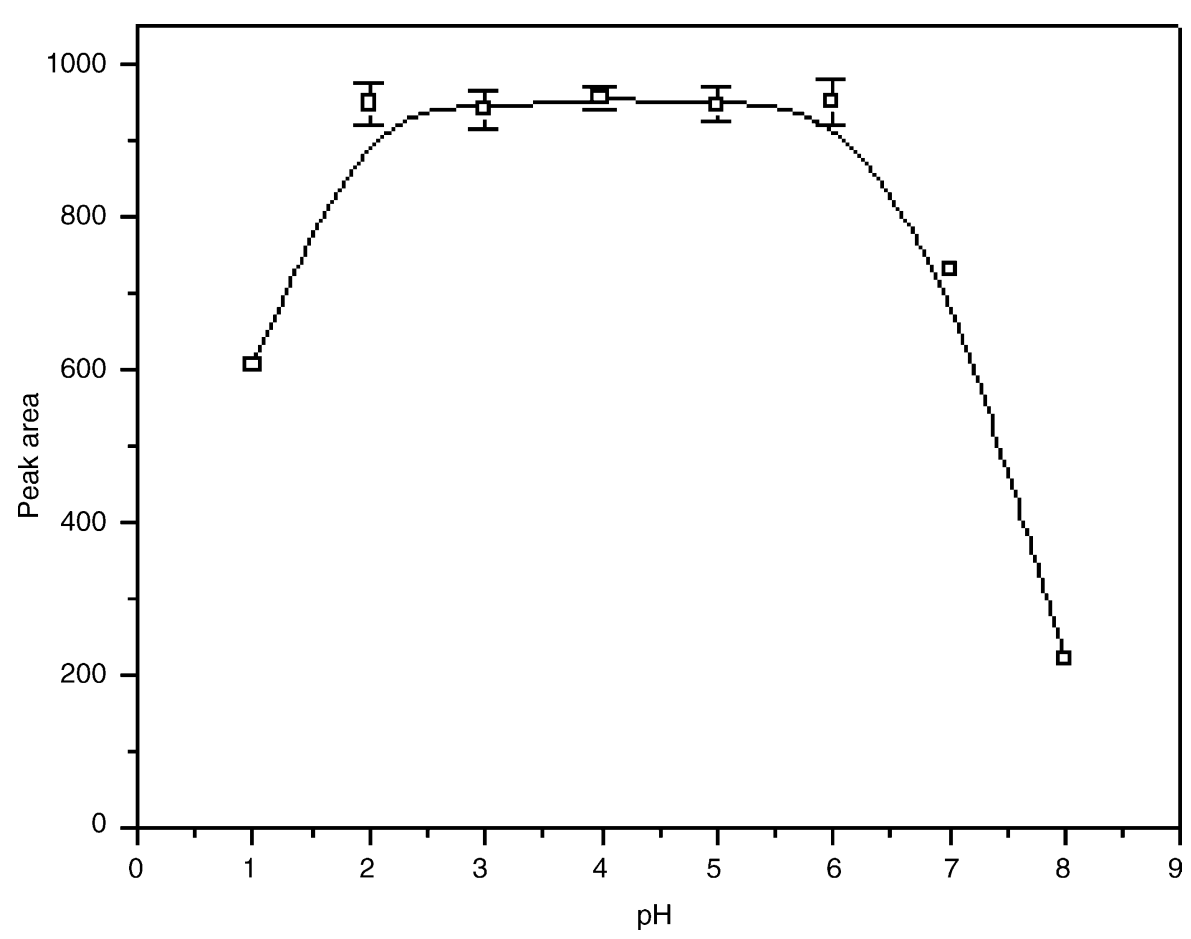

Fig. 2. Effect of $\mathrm{pH}$ on derivatization of formaldehyde. HCHO: $80 \mu \mathrm{mol} \mathrm{L}^{-1}$, DNPH: $240 \mu \mathrm{mol} \mathrm{L}^{-1}$, derivatization time: $30 \mathrm{~min}$.

detected, whereas with increasing DMSO concentrations, the signal of HCHO-DNPH increased in a hyperbolic fashion. Above $2 \mathrm{mmol} \mathrm{L}^{-1}$ DMSO, the signal was independent of DMSO concentration, which indicated the concentration of DMSO was enough to trap the ${ }^{\bullet} \mathrm{OH}$ generated by systems studied in at least $60 \mathrm{~min}$.
Since formaldehyde is a compound easy to be oxidized, $200 \mathrm{nmol} \mathrm{HCHO}$ were added to $\mathrm{Fe}^{3+}$-bipy $/ \mathrm{H}_{2} \mathrm{O}_{2}$ system contained DMSO of different concentration to investigate the recovery of $\mathrm{HCHO}$ to make sure that $\mathrm{HCHO}$ was not further oxidized by ${ }^{\bullet} \mathrm{OH}$. The results were listed in Table 1. It can be seen that $\mathrm{HCHO}$ is not oxidized by ${ }^{\bullet} \mathrm{OH}$ even in the

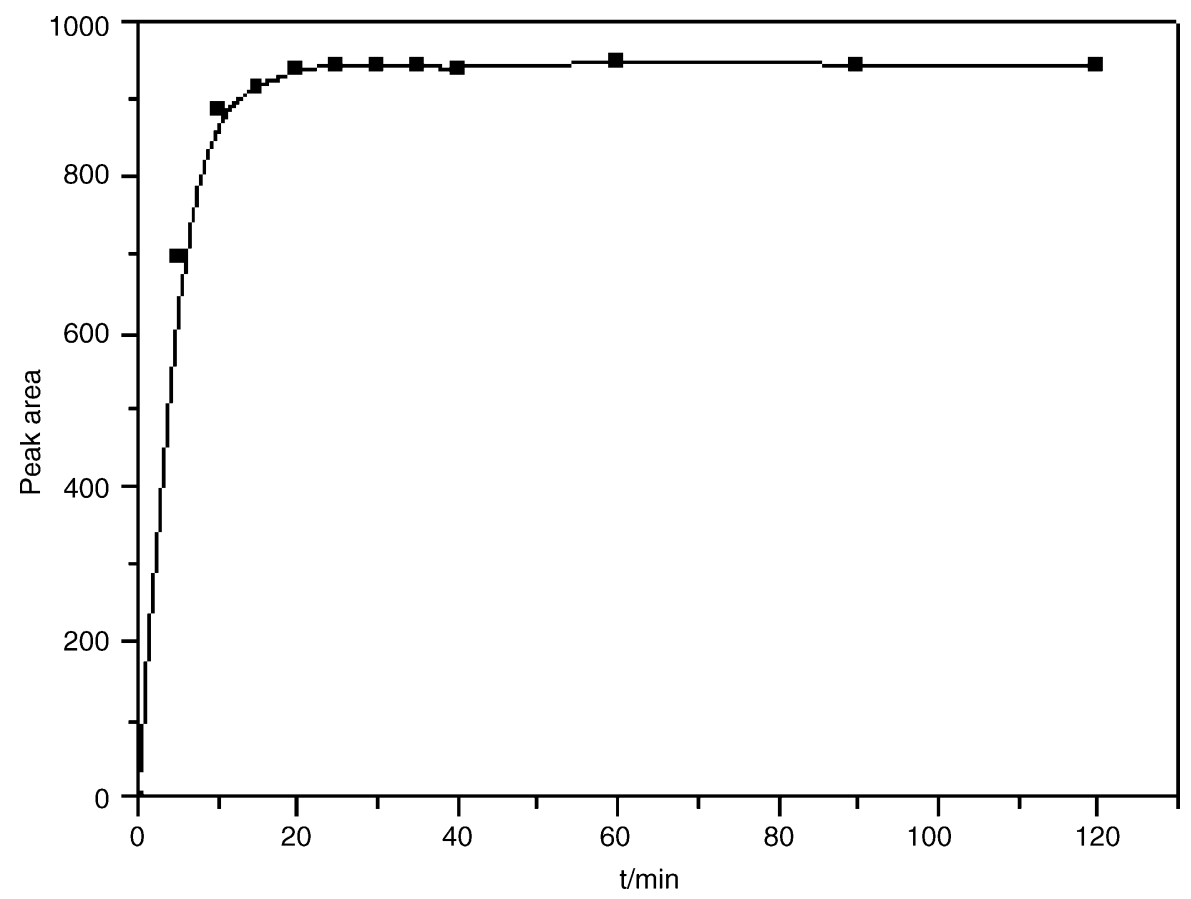

Fig. 3. . Effect of derivatization time on the peak area of HCHO-DNPH. HCHO: $80 \mu \mathrm{mol} \mathrm{L}^{-1}$, DNPH: $240 \mu \mathrm{mol} \mathrm{L}^{-1}$, pH: 4.0. 


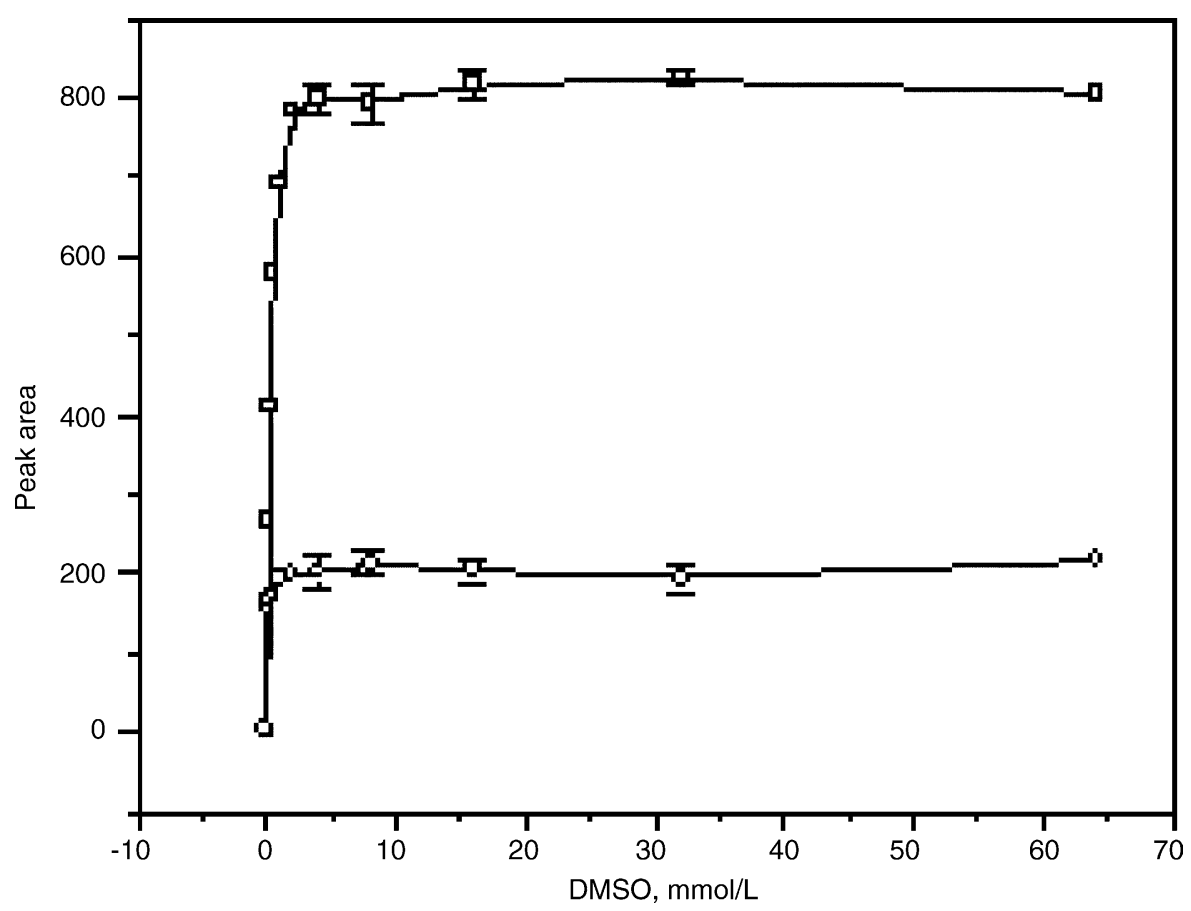

Fig. 4. Effect of DMSO concentration on the trapping of hydroxyl radicals. ( $\square) \mathrm{Fe}^{3+}$-bipy/ $\mathrm{H}_{2} \mathrm{O}_{2}$ system; $(\bigcirc)$ Fenton reaction. $\mathrm{Fe}^{2+}$ or Fe $\mathrm{Fe}^{3+}$-bipy: $0.2 \mathrm{mmol} \mathrm{L}^{-1}$, $\mathrm{H}_{2} \mathrm{O}_{2}: 8 \mathrm{mmol} \mathrm{L}^{-1}$, reaction time: $60 \mathrm{~min}$.

Table 1

Recovery of HCHO at different DMSO concentration

\begin{tabular}{lllll}
\hline Concentration of DMSO $\left(\mathrm{mmol} \mathrm{L}^{-1}\right)$ & HCHO generated & HCHO added & HCHO founded & Recovery $(\%)$ \\
\hline 25 & 193 & 200 & 398 & 103 \\
2.5 & 188 & 200 & 383 & 97.5 \\
0.25 & 121 & 200 & 309 & 94 \\
0 & 0 & 200 & 208 & 104 \\
\hline
\end{tabular}

absence of DMSO. $1000 \mathrm{nmol}$ methanol were also added to the $\mathrm{Fe}^{3+}$-bipy $/ \mathrm{H}_{2} \mathrm{O}_{2}$ system to investigate the possible interference of methanol, which was also a product of the reaction between DMSO and hydroxyl radicals. The results (Table 2) show that without DMSO or with DMSO of low concentration $\left(0.25 \mathrm{mmol} \mathrm{L}^{-1}\right)$, methanol will be oxidized to formaldehyde, to interfere the determination of formaldehyde. But with the DMSO concentration higher than $2.5 \mathrm{mmol} \mathrm{L}^{-1}$, methanol cannot be oxidized, since most hydroxyl radicals are trapped by DMSO. From the results above, it can be safely concluded that: (i) $\mathrm{HCHO}$ is a stable product under our experimental conditions; (ii) methanol, another product

Table 2

Influence of $\mathrm{CH}_{3} \mathrm{OH}$ on the detection of $\mathrm{HCHO}$ at different DMSO concentration

\begin{tabular}{llll}
\hline $\begin{array}{l}\text { Concentration of } \\
\text { DMSO } \\
\left(\mathrm{mmol} \mathrm{L}^{-1}\right)\end{array}$ & $\begin{array}{l}\mathrm{HCHO} \\
\text { generated } \\
(\mathrm{nmol})\end{array}$ & $\begin{array}{l}\mathrm{CH}_{3} \mathrm{OH} \\
\text { added } \\
(\mathrm{nmol})\end{array}$ & $\begin{array}{l}\mathrm{HCHO} \\
\text { founded } \\
(\mathrm{nmol})\end{array}$ \\
\hline 25 & 203 & 1000 & 213 \\
2.5 & 205 & 1000 & 198 \\
0.25 & 113 & 1000 & 138 \\
0 & 0 & 1000 & 66.9 \\
\hline
\end{tabular}

of the reaction between DMSO and hydroxyl radicals, cannot be oxidized to formaldehyde with a concentration of DMSO high enough. In all our studies, $250 \mathrm{mmol} \mathrm{L}^{-1}$ of the DMSO concentration was used to trap most hydroxyl radicals.

\subsection{The quantitative relationship between hydroxyl radicals and formaldehyde}

Hydroxyl radicals were generated quantitatively by the Fenton reaction by, adding a small known amount of $\mathrm{H}_{2} \mathrm{O}_{2}$ slowly into a well-stirred solution of $250 \mathrm{mmol} \mathrm{L}^{-1} \mathrm{DMSO}$ containing excess $\mathrm{Fe}^{2+}\left(10 \mathrm{mmol} \mathrm{L}^{-1}\right)$. It was expected that the slow addition of $\mathrm{H}_{2} \mathrm{O}_{2}$ into excess $\mathrm{Fe}^{2+}$ would minimize the reaction of ${ }^{\bullet} \mathrm{OH}$ with $\mathrm{H}_{2} \mathrm{O}_{2}$ to yield 1 mol of ${ }^{\bullet} \mathrm{OH}$ for each mole of $\mathrm{H}_{2} \mathrm{O}_{2}$ [32,33]. The relationship between the formaldehyde detected and the hydroxyl radicals generated was shown in Fig. 5. These results indicated that there was good quantitative relationship between hydroxyl radicals and formaldehyde. One mole of formaldehyde was generated from 2.17 mol of hydroxyl radicals reacting with DMSO, which was consistent with the calculated generation of formaldehyde according Eqs. (1), (3) and (4). 


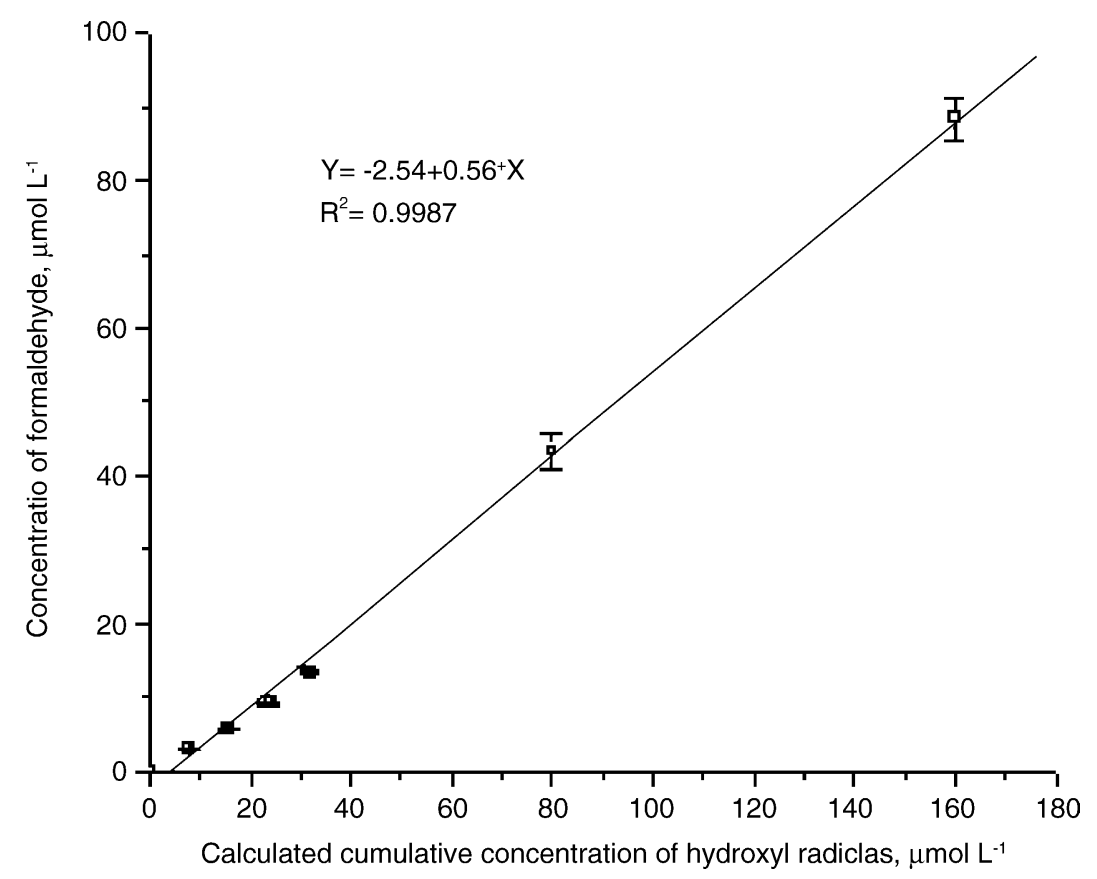

Fig. 5. The quantitative relationship between hydroxyl radicals and formaldehyde.

\subsection{Studying on the generation of hydroxyl radicals by AOPs systems}

Fig. 6 demonstrates the time course of ${ }^{\bullet} \mathrm{OH}$ formation in various systems. In systems of $\mathrm{Fe}^{2+} / \mathrm{H}_{2} \mathrm{O}_{2}, \mathrm{Fe}^{3+} / \mathrm{H}_{2} \mathrm{O}_{2}$, the average generation rate of ${ }^{\circ} \mathrm{OH}$ in $120 \mathrm{~min}$ were 1.39 and $0.38 \mathrm{nmnol} \mathrm{min}^{-1}$, respectively. EDTA prevents the generation of $\bullet \mathrm{OH}[30,34]$, the average generation rate of - $\mathrm{OH}$ in $120 \mathrm{~min}$ were only 0.26 and $0.06 \mathrm{nmnol} \mathrm{min}^{-1}$ for $\mathrm{Fe}^{2+}-\mathrm{EDTA} / \mathrm{H}_{2} \mathrm{O}_{2}$ and $\mathrm{Fe}^{3+}$-EDTA/ $\mathrm{H}_{2} \mathrm{O}_{2}$, respectively. $\mathrm{Fe}^{3+}$-bipy $/ \mathrm{H}_{2} \mathrm{O}_{2}$ was the best system for the generation of $\bullet \mathrm{OH}$, in which the average generation rate in 120 min was up to $6.57 \mathrm{nmnol} \mathrm{min}^{-1}$.

In all the systems studied, a rapid generation of $\bullet \mathrm{OH}$ was observed in the first $5 \mathrm{~min}$ and then following by a slower rate. The initial rate and the followed slower rate were calculated and listed in Table 3 . The generation rate of ${ }^{\bullet} \mathrm{OH}$ in $\mathrm{Fe}^{2+} / \mathrm{H}_{2} \mathrm{O}_{2}$ was up to $17.6 \mathrm{nmnolmin}{ }^{-1}$, but dropped sharply in the following reaction with a rate of only 0.48 nmol min ${ }^{-1}$. It was because $\mathrm{Fe}^{2+}$ was oxidized to $\mathrm{Fe}^{3+}$ quickly, and the later was reduced to $\mathrm{Fe}^{2+}$ by $\mathrm{H}_{2} \mathrm{O}_{2}$ slowly to form the chain reactions:

$$
\begin{aligned}
& \mathrm{Fe}^{2+}+\mathrm{H}_{2} \mathrm{O}_{2} \rightarrow \mathrm{Fe}^{3+}+\cdot{ }^{\circ} \mathrm{H}+\mathrm{OH}^{-} \\
& k=58 \mathrm{~mol} \mathrm{~L}^{-1} \mathrm{~s}^{-1} \\
& \mathrm{Fe}^{3+}+\mathrm{H}_{2} \mathrm{O}_{2} \stackrel{\text { slow }}{\longrightarrow} \mathrm{Fe}^{2+}+{ }^{\circ} \mathrm{O}_{2} \mathrm{H}+\mathrm{H}^{+} \\
& k=0.02 \mathrm{~mol} \mathrm{~L}^{-1} \mathrm{~s}^{-1}
\end{aligned}
$$

$\mathrm{UV} / \mathrm{H}_{2} \mathrm{O}_{2}$ and $\mathrm{UV} / \mathrm{Fe}^{2+} / \mathrm{H}_{2} \mathrm{O}_{2}$ systems showed high generation rate of ${ }^{\bullet} \mathrm{OH}$, because the ultraviolet irradiation can

Table 3

The generation rate of hydroxyl radicals of various systems

\begin{tabular}{lcl}
\hline Systems & $\begin{array}{l}\text { Average generation rate in the } \\
\text { first } 5 \mathrm{~min}, \mathrm{nmol} \mathrm{min}\end{array}$ & $\begin{array}{l}\text { Average generation rate from } \\
10 \text { to } 120 \mathrm{~min}, \mathrm{nmol} \mathrm{min}^{-1}\end{array}$ \\
\hline $\mathrm{Fe}^{2+} / \mathrm{H}_{2} \mathrm{O}_{2}$ & 17.6 & 0.48 \\
$\mathrm{Fe}^{3+} / \mathrm{H}_{2} \mathrm{O}_{2} ;$ & 1.56 & 0.32 \\
$\mathrm{Fe}^{2+}$-bipy $/ \mathrm{H}_{2} \mathrm{O}_{2}$ & 9.3 & 2.06 \\
$\mathrm{Fe}^{3+}$-bipy $/ \mathrm{H}_{2} \mathrm{O}_{2}$ & 22.4 & 4.49 \\
$\mathrm{Fe}^{2+}$-EDTA $/ \mathrm{H}_{2} \mathrm{O}_{2}$ & 3.68 & 0 \\
$\mathrm{Fe}^{3+}$-EDTA $/ \mathrm{H}_{2} \mathrm{O}_{2}$ & 1.32 & 0 \\
$\mathrm{UV}-\mathrm{H}_{2} \mathrm{O}_{2}$ & 6.72 & 2.40 \\
$\mathrm{UV}-\mathrm{Fe}^{2+} / \mathrm{H}_{2} \mathrm{O}_{2}$ & 17.9 & 4.19 \\
\hline
\end{tabular}



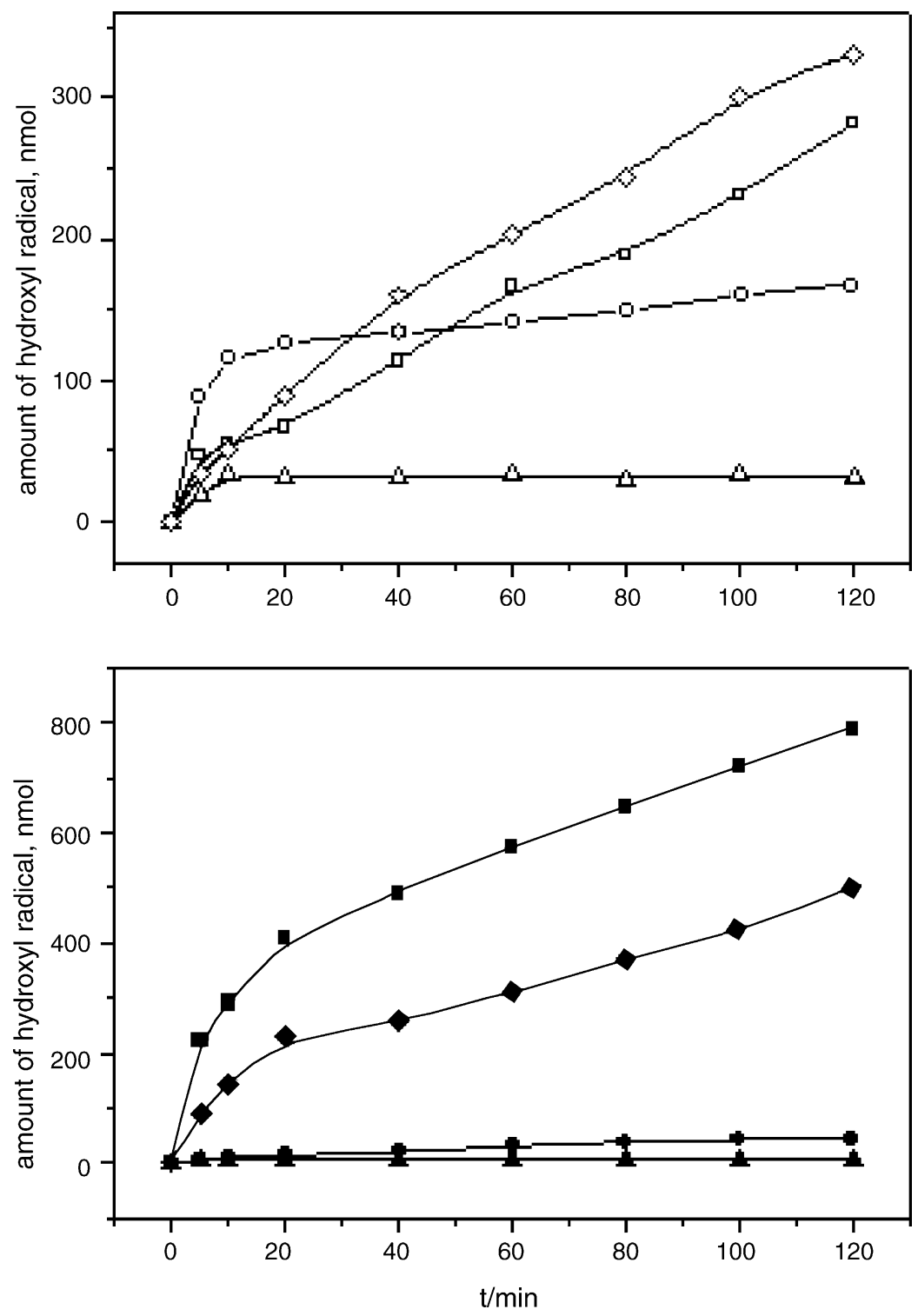

Fig. 6. Generation of hydroxyl radicals by different systems. ( $\bigcirc) \mathrm{Fe}^{2+} / \mathrm{H}_{2} \mathrm{O}_{2} ;(\bullet) \mathrm{Fe}^{3+} / \mathrm{H}_{2} \mathrm{O}_{2}(\square) \mathrm{Fe}^{2+}-$ bipy/ $\mathrm{H}_{2} \mathrm{O}_{2} ;(\mathbf{\square}) \mathrm{Fe}^{3+}-$ bipy/ $\mathrm{H}_{2} \mathrm{O}_{2} ;(\triangle) \mathrm{Fe}^{2+}$ EDTA $/ \mathrm{H}_{2} \mathrm{O}_{2} ;(\boldsymbol{\Delta}) \mathrm{Fe}^{3+}$-EDTA $/ \mathrm{H}_{2} \mathrm{O}_{2} ;(\diamond)$ : UV/ $\mathrm{H}_{2} \mathrm{O}_{2} ;(\diamond) \mathrm{UV} / \mathrm{Fe}^{2+} / \mathrm{H}_{2} \mathrm{O}_{2}$. DMSO: $250 \mathrm{mmol} \mathrm{L}{ }^{-1}, \mathrm{Fe}^{2+}, \mathrm{Fe}^{3+}$ and their complexes: $0.2 \mathrm{mmol} \mathrm{L}^{-1}, \mathrm{H}_{2} \mathrm{O}_{2}$ : $8 \mathrm{mmol} \mathrm{L}-1$, the generation of hydroxyl radicals by $\mathrm{UV}-\mathrm{H}_{2} \mathrm{O}_{2}$ and $\mathrm{UV}-\mathrm{Fe}^{2+} / \mathrm{H}_{2} \mathrm{O}_{2}$ were carried out under a $40 \mathrm{~W}$ ultraviolet lamp with an irradiation area of $0.79 \mathrm{~cm}^{2}$.

induce the homolytic cleavage of hydrogen peroxide to generate hydroxyl radicals $[35,36]$. Compared to $\mathrm{Fe}^{2+} / \mathrm{H}_{2} \mathrm{O}_{2}$ system, $\mathrm{Fe}^{2+}$-bipy $/ \mathrm{H}_{2} \mathrm{O}_{2}$ had a lower generation rate of hydroxyl radicals in the first $5 \mathrm{~min}$, but a higher rate in the following process. $\mathrm{Fe}^{3+}$-bipy $/ \mathrm{H}_{2} \mathrm{O}_{2}$ systems were found to have much higher generation rate of ${ }^{\bullet} \mathrm{OH}$ than that $\mathrm{Fe}^{3+} / \mathrm{H}_{2} \mathrm{O}_{2}$. The changes of the UV-vis spectrogram during the reaction between $\mathrm{Fe}^{3+}$-bipy $/ \mathrm{H}_{2} \mathrm{O}_{2}$ were studied. The results (data not shown) showed upon the addition of $\mathrm{H}_{2} \mathrm{O}_{2}$ to $\mathrm{Fe}^{3+}$-bipy solution, the absorption at $520 \mathrm{~nm}$, which was the characteristic absorption of $\mathrm{Fe}^{2+}$-bipy, increased and reached max in about forty min. This phenomenon indicated that the reduction of $\mathrm{Fe}^{3+}$-bipy to $\mathrm{Fe}^{2+}$-bipy by $\mathrm{H}_{2} \mathrm{O}_{2}$ was much easier than the reduction of $\mathrm{Fe}^{3+}$ to $\mathrm{Fe}^{2+}$ by $\mathrm{H}_{2} \mathrm{O}_{2}$, resulting the high yield of hydroxyl radicals by the blow reactions:

$$
\begin{aligned}
& \mathrm{Fe}^{3+} \text {-bipy }+\mathrm{H}_{2} \mathrm{O}_{2} \stackrel{\text { fast }}{\longrightarrow} \mathrm{Fe}^{2+} \text {-bipy }+\cdot{ }^{\bullet} \mathrm{O}_{2} \mathrm{H}+\mathrm{H}^{+} \\
& \mathrm{Fe}^{2+} \text {-bipy }+\mathrm{H}_{2} \mathrm{O}_{2} \rightarrow \mathrm{Fe}^{3+} \text {-bipy }+\cdot{ }^{\bullet} \mathrm{OH}+\mathrm{OH}^{-}
\end{aligned}
$$

It was surprising that $\mathrm{Fe}^{3+}$-bipy $/ \mathrm{H}_{2} \mathrm{O}_{2}$ had a higher generation rate than that of $\mathrm{Fe}^{2+}$-bipy/ $\mathrm{H}_{2} \mathrm{O}_{2}$. It should be noted that the absorption at $520 \mathrm{~nm}$ of $\mathrm{Fe}^{3+}$-bipy after the addition of $\mathrm{H}_{2} \mathrm{O}_{2}$ was only $80 \%$ of the absorption of equivalent mol Fe ${ }^{2+}$-bipy. This indicated that there were probably other generation pathway of ${ }^{\bullet} \mathrm{OH}$ besides Reactions (7) and (8). According to the statements of Gozzo [9] and Meunier [37], a possible mechanism was proposed, in which high-valency 
Table 4

Comparison of different methods for the determination of hydroxyl radicals

\begin{tabular}{|c|c|c|c|c|c|}
\hline Trapping reagent & Quantitative product & Separation & Detector & Detection limit & Ref. \\
\hline Salicylic acid & 2,3-dHBA ${ }^{\mathrm{a}}, 2,5-\mathrm{dHBA}$, catechol & HPLC, 23 min & UV & $5-50 \mu \mathrm{g} \mathrm{L}^{-1}$ & [14] \\
\hline Salicylic acid & $\begin{array}{l}\text { 2,3-dHBA, 2,4-dHBA, 2,5-dHBA, } \\
\text { 2,6-dHBA, catechol }\end{array}$ & $\mathrm{GC}, 20 \mathrm{~min}$ & MS & $0.05-1 \mu \mathrm{mol} \mathrm{L}^{-1}$ & {$[15]$} \\
\hline DMSO & $o$-Methylhydroxylamine & HPLC, $11 \mathrm{~min}$ & Fluorescence & $3.5 \mathrm{nmol} \mathrm{L}^{-1}$ & [16] \\
\hline DMSO & $\operatorname{MSA}^{\mathrm{b}}$ & HPLC 6 min & UV & $8 \mu \mathrm{gL}^{-1}$ & [21] \\
\hline DMSO & $\mathrm{HCHO}$ & HPLC 7 min & UV & $9.8 \mu \mathrm{gL}^{-1}\left(0.54 \mu \mathrm{mol} \mathrm{L}^{-1}\right)$ & This work \\
\hline
\end{tabular}

a 2,3-Dihydroxybenzoic acid.

b Methane sulfinic acid.

species of iron were involved:

bipy-Fe ${ }^{\mathrm{III}}+\mathrm{H}_{2} \mathrm{O}_{2} \rightarrow$ bipy-Fe $\mathrm{IV}^{\mathrm{IV}}-\mathrm{OH}+\bullet{ }^{\bullet} \mathrm{OH}$

bipy-Fe ${ }^{\mathrm{IV}}-\mathrm{OH} \rightarrow$ bipy-Fe $\mathrm{F}^{\mathrm{III}}+{ }^{\bullet} \mathrm{OH}$

\section{Conclusions}

The proposed method for the detection of hydroxyl radicals in AOPs is simple, sensitive and easy to be operated. A summary of the comparison of different methods for the determination of hydroxyl radicals is given in Table 4 . For the current method, only one quantitative product is produced in the detection system, which makes the separation and quantification much easier. Because DMSO is highly water soluble, nontoxic at relatively high concentrations and has an appreciable rate of interaction with hydroxyl radical, it has been proved to be an ideal trap for hydroxyl radical. Formaldehyde and DNPH are available readily, which makes it convenient for the detection of hydroxyl radicals generated in AOPs. The proposed method has been used to determination of the yield of hydroxyl radicals in various AOPs to compare their oxidation ability. However, it should be noted that this method is not suitable for the determination of hydroxyl radicals when there are a large number of other organic substrates, which may have a major effect on the chemistry of methyl radicals.

\section{Acknowledgement}

This work was financially supported by the National Basic Research Program of China and the National Natural Science Foundation of China (2003CB415001, 20137010).

\section{References}

[1] L. Sanchez, J. Peral, X. Doménech, Appl. Catal. B: Environ. (1998) 19.

[2] E. Lipczynska-Kochany, Environ. Technol. 12 (1991) 87-92.

[3] M. Fukushima, K. Tatsumi, Environ. Sci. Technol. 35 (2001) 1771-1776.
[4] E. Pramauro, M. Vincenti, Environ. Sci. Technol. 27 (1993) 1790-1795.

[5] W. Chu, C.K. Law, Wat. Res. 37 (2003) 2339-2346.

[6] H. Gallard, J.D. Laat, Chemosphere 42 (2001) 405-413.

[7] M.A. Oturan, J. Peiroten, P. Chartrin, A.J. Acher, Environ. Sci. Technol. 34 (2000) 3474-3479.

[8] F. Cheng, W. Ma, J. He, J. Zhao, Environ. Sci. Technol. 106 (2002) 9485-9490.

[9] F. Gozzo, J. Mol. Catal. A: Chem. 171 (2001) 1-22.

[10] H.B. Dunford, Coord. Chem. Rev. 233/234 (2002) 311-318.

[11] M. Geoffroy, P. Lambelet, P. Richert, J. Agric. Food Chem. 48 (2000) 974-978.

[12] J. Kochany, J.R. Bolton, J. Phys. Chem. 95 (1991) 5116-5120.

[13] D.A. Das, G.A. Cordis, J. Chromatogr. A 536 (1991) 273-282.

[14] J.F. Jen, M.F. Leu, Y.C. Yang, J. Chromatogr. A 796 (1998) 283-288.

[15] X. Luo, D.C. Lehotay, Clin. Biochem. 30 (1997) 41-46.

[16] C. Coudara, M. Martin, M. Fatome, A. Favier, Anal. Biochem. 227 (1995) 101-111.

[17] B. Li, P.L. Gutierrez, N.V. Blough, Anal. Chem. 69 (1997) 4295-4302.

[18] E.E. Roden, J.M. Zachara, Environ. Sci. Technol. 30 (1996) $1618-1628$.

[19] J. Howsawkeng, R.J. Watts, D.L. Washington, A.L. Teel, T.F. Hess, R.L. Crawford, Environ. Sci. Technol. 35 (2001) 2961-2966.

[20] C.F. Babbs, D.W. Griffin, Free Rad. Biol. Med. 6 (1989) 493-503.

[21] C.F. Babbs, M.J. Gale, Anal. Biochem. 163 (1987) 63-73.

[22] S. Fukui, Y. Hanasaki, H. Ogawa, J. Chromatogr. A 630 (1993) 187-193.

[23] L.S. Jahnke, Anal. Biochem. 269 (1999) 273-277.

[24] H. Bardouki, M.B. da Rosa, N. Mihalopoulos, W.-U. Palm, C. Zetzsch, Atmos. Envrion. 36 (2002) 4627-4634.

[25] Y. Zuo, Chemosphere 51 (2003) 175-179.

[26] B. Li, P.L. Gutierrez, P. Amstad, N.V. Blough, Chem. Res. Toxicol. 12 (1999) 1042-1049.

[27] S.M. Klein, G. Cohen, A.R. Cederbaum, Biochem. 20 (1981) 6006-6012.

[28] M.T. Oliva-Teles, P. Paíga, C.M. Delerue-Matos, M.C.M. AlvimFerraz, Anal. Chim. Acta 467 (2002) 97-103.

[29] H. Zegota, J. Chromatogr. A 863 (1999) 227-233.

[30] Y. Sun, J.J. Pignatello, J. Agric. Food. Chem. 40 (1992) 322-327.

[31] M.S. Niassary, F. Farzaneh, M. Ghandi, J. Mol. Catal. A. 175 (2001) 105-110.

[32] C. Walling, Accounts Chem. Res. 8 (1975) 125-131.

[33] M.G. Steiner, C.F. Babbs, Arch. Biochem. Biophy. 278 (1990) 478-481.

[34] W.H. Koppenol, J. Free Rad. Biol. Med. 1 (1985) 281-285.

[35] R. Zepp, B. Faust, J. Hoigné, Environ. Sci. Technol. 26 (1995) 313-319.

[36] Y. Zuo, Geochim. Cosmochim. Acta 59 (1995) 3123-3130.

[37] B. Meunier, Chem. Rev. 92 (1992) 1411-1456. 